\title{
Reflexiones para transitar de la banalidad del mal a la banalidad del heroísmo.
}

\author{
Reseña El Efecto Lucifer: El porqué de la maldad. Philip Zimbardo
}

\author{
Reflections to move from the banality of evil to the banality of heroism
}

Rocío del Carmen Hernández-Hernández ${ }^{a}$, Doris Lauy Beatríz Dzib Moo ${ }^{b}$

\begin{abstract}
:
This paper presents a review of the book: The Lucifer Effect: The Why of Evil by Philip Zimbardo, which integrates 16 chapters where he discusses the psychology of evil and how the situational and systemic factors that drive it often facilitate the relationship of abusive and destructive acts against people. Drawing on historical examples and his own research, the author details how situational forces and group dynamics interact to turn decent men and women into monsters, and how systems provide the institutional support, authority, and resources to that people in specific situations act as they do and have despicable behaviors.
\end{abstract}

Keywords:

Cognitive dissonance, rationalize, banality of evil, banality of heroism

Resumen:

Este trabajo presenta una reseña del libro: El Efecto Lucifer: El porqué de la maldad de Philip Zimbardo, el cual integra 16 capítulos donde diserta sobre la psicología de la maldad y de cómo los factores situacionales y sistémicos que la impulsan suelen facilitar la relación de actos abusivos y destructivos contra las personas. El autor, basándose en ejemplos históricos y en sus propias investigaciones, detalla cómo interactúan las fuerzas situacionales y la dinámica de grupos para convertir a hombres y mujeres decentes en monstruos y, cómo los sistemas proporcionan el apoyo institucional, la autoridad y los recursos, para que las personas en situaciones específicas, actúen como lo hacen y tengan conductas deleznables.

\section{Palabras Clave:}

Disonancia cognitiva, racionalizar, banalidad del mal, banalidad del heroísmo.

\section{Introducción}

El interés por la literatura referida al comportamiento humano y específicamente, nuestra curiosidad por la naturaleza humana, nos condujo a adentrarnos en el campo del comportamiento social y de la psicología del mal. Desde nuestra perspectiva, el libro que mejor expresa lo referente a la naturaleza del mal y la vulnerabilidad humana es el que lleva por título "El Efecto Lucifer" de la autoría de Philip Zimbardo. Pero antes de describir la obra, resulta fundamental conocer algunos datos sobre el autor y sus investigaciones, así como sus aportes a la ciencia de la psicología social.

Philip Zimbardo es doctor en Psicología Social por la Universidad de Yale e investigador del comportamiento humano; impartió cátedra en la misma universidad y actualmente, es profesor emérito de la Universidad de Stanford, donde fue docente durante 50 años.

Su línea de investigación está centrada en el comportamiento social y análisis sobre la naturaleza del mal, así como en el estudio de las conductas prosociales. Ha publicado una vasta gama de literatura científica, de la cual en particular citamos: La paradoja del tiempo, 2008 y Experimento de la prisión de Stanford, 1971

El libro: El efecto Lucifer: El porqué de la maldad, aborda el estudio de la conducta humana y su deshumanización, la brillantez de la obra radica en la comprensión plena de la dinámica de la conducta de las personas, la cual exige reconocer el alcance y los límites del poder personal, del

\footnotetext{
Autor de Correspondencia, Universidad Juárez Autónoma de Tabasco, https://orcid.org/0000-0002-0458-8468 Email: rocahdhd@hotmail.com 
poder situacional y del poder sistémico. A partir de sus innovadoras investigaciones y estudios, el autor contribuye a la comprensión sobre la psicología del mal y de los factores que influyen para que una buena persona termine actuando con maldad.

A lo largo del texto, Zimbardo da razones sobre cómo las fuerzas situacionales pueden influir en la conducta individual y en la que es importante ascender por la cadena explicativa del análisis de la persona a las situaciones y de la situación al sistema para comprender las conductas deleznables. De ahí la importancia y el valor científico de esta obra, los cuales radican en su capacidad de estudiar, en su conjunto, tres perspectivas sobre el mal.

Dichas perspectivas son: el factor disposicional (genética), el factor situacional (puestos 0 circunstancias), y el factor sistémico (instituciones/élite de poder), para comprender el porqué, la gente hace lo que hace. El libro nos conduce a reflexionar sobre nuestra cultura individualista, en la cual prevalece el prejuicio disposicional, ya que cuando intentamos entender las causas de la conducta de otras personas, tendemos a sobrevalorar el peso de este factor; es decir, la genética y los rasgos de personalidad, entre otros, y a infravalorar la importancia de las situaciones y el marco en que se encuentra, pues se ignora el sistema que las genera. Un ejemplo de ello es el sistema jurídico, el cual exige encausar personas y no situaciones o sistemas por un acto delictivo.

El autor nos invita a no inclinarnos y evitar el criterio disposicional, cuando intentamos entender las causas de una conducta inusual, sugiere iniciar nuestra búsqueda de significado, planteando preguntas tales como: ¿qué condiciones pueden contribuir a determinadas reacciones?, ¿qué circunstancias pueden generar una conducta?, ¿qué aspectos tiene la situación, considerando el punto de vista de quienes se encuentran en ella?

El entendimiento de la conducta humana, dice el autor, exige reconocer el alcance y los límites de los poderes personales, situacionales y sistémicos, por lo que es imperativo escalar de la simple observación de la conducta personal del sujeto, al estudio de las circunstancias y del entorno que rodea a la persona. En este contexto, el libro nos otorga un marco explicativo para entender el comportamiento humano y señala algunos aspectos importantes referidos al poder de las normas y el papel que juegan éstas en la conducta social.

Zimbardo señala que son los sistemas los que construyen las instituciones y son estas organizaciones las que invisten de un poder situacional (puesto) a las personas, las cuales con la autoridad conferida crean normas de control que obligan a los demás a cumplirlas.
De ahí que el autor nos conduce a reflexionar sobre cómo los roles están ligados a un puesto, y de cuando los roles se introyectan y se hacen reales, permitiendo el control y posible abuso de las personas a través del establecimiento de normas. Es decir, cómo un individuo al frente de un puesto o cargo, da vida a un personaje y suele representar papeles que poco tienen que ver con su identidad personal, o también por el contrario, el rol del nuevo puesto les permita aflorar lo que de por sí eran, pero no se atrevían a hacer por estar desprovistos del poder que otorga la circunstancia.

En este sentido, el autor menciona: "en el nuevo puesto o cargo, las personas aprenden a hablar, a caminar, a comer e incluso a pensar y sentir como exige el puesto que representan" y su formación profesional, les permite mantener la separación entre "personaje" e identidad y mantener su personalidad en un segundo plano, aun cuando represente un papel que puede ser totalmente diferente a su manera de ser. Ante esto, Zimbardo reconoce que a veces estos límites se confunden, incluso hasta un profesional entrenado puede seguir metido en su papel aun cuando ya ha caído el telón, se sumerge tanto en la intensidad del papel, que el papel acaba rigiendo su vida fuera del escenario.

En efecto, el libro ofrece conocimientos y experiencias relevantes a lo largo de sus 16 capítulos, donde diserta sobre el comportamiento humano y su tendencia a la deshumanización, nos ofrece pruebas abundantes de cuando las personas inteligentes hacen tonterías, las personas cuerdas hacen locuras y las personas morales hacen cosas inmorales, y lo peor de todo, es que cuando las han hecho, ofrecen "buenas" racionalizaciones del por qué han hecho lo que no pueden negar que han hecho. La gente tiene más capacidad para racionalizar que para ser racional, es decir, tiende a justificar las discrepancias entre su moralidad privada y los actos que la contradicen.

Ante este hecho, en el libro se menciona lo referente a la disonancia cognitiva que racionaliza el mal, a lo cual señala el autor, que es el resultado de representar en público un papel que va en contra de las propias creencias; y es ahí, donde surge la disonancia cognitiva, por lo que debemos aprender a ser plenamente conscientes de las presiones situacionales que nos empujan a realizar el acto discrepante.

El autor devela cómo la disonancia cognitiva es una de las causas principales de que se acaben interiorizando las conductas públicas de un rol y de la adquisición de estilos cognitivos y afectivos que contribuyen a un comportamiento cada vez más autoritario, incluso hasta malévolo, por lo que, ante el hecho de llevar a cabo algún acto disonante con las creencias personales, se suele buscar sentido y hallar razones de por qué se hizo lo que se hizo. 
Ciertamente, dice Zimbardo, que ante la exigencia de un rol que trae consigo acciones negativas, la persona suele echar mano de todas las defensas psicológicas que tiene a su alcance para no afrontar la realidad y sufre una especie de agarrotamiento psíquico, que separa las emociones de la cognición. Es así que ese estado de desvinculación facilita la violencia y las funciones mentales cambian, viven en un presente dilatado, donde pasado y futuro son irrelevantes, los sentimientos dominan sobre la razón y la acción domina sobre la reflexión. La persona investida por el sistema o la situación, la cual está instada a desempeñar un rol, debe estar alerta para detectar cuándo el poder situacional del cargo le da permiso para liberar sus impulsos, para seguir o imponer directrices a las que normalmente se opondría.

El análisis sobre la psicología de la maldad, es decir, la psicología de la deshumanización, nos permite observar las malas prácticas corporativas y el genocidio organizado, y cómo se puede seducir a una persona moral para que actúe de manera inmoral, sobre todo ante factores situacionales y sistémicos que la impulsan y en la que esos factores, suelen facilitar la relación de actos abusivos y destructivos contra las personas.

El texto expone cómo las situaciones (puestos) son creadas por los sistemas y cómo los sistemas proporcionan el apoyo institucional, la autoridad y los recursos que permiten que las personas en situaciones específicas actúen como lo hacen. Señala la facilidad con la que las buenas personas pueden transformarse en seres malévolos, si el poder situacional no se limita. Es decir, aborda la dramática transformación de la naturaleza humana por el poder de las situaciones sociales y los sistemas.

Philip Zimbardo alude a la extrema maleabilidad de la naturaleza humana y nos invita a cuestionar hasta qué punto nos conocemos a nosotros mismos, para saber con seguridad, cómo actuaríamos en un entorno nuevo y sometidos a presiones situacionales muy intensas; nos dice que cada uno de nosotros tiene la capacidad de ser santo o pecador; altruista o egoísta; bondadoso o cruel; malhechor o víctima. Quizá sean nuestras circunstancias sociales las que deciden cuál de nuestras muchas "plantillas mentales", cuál de nuestros potenciales vamos a desarrollar.

El autor describe con brillantez, la banalidad del mal y la banalidad del heroísmo. En lo que respecta a la banalidad del mal, señala que existen personas comunes, corrientes y terroríficamente normales que cometen injusticias y delitos en circunstancias que casi le impiden saber o intuir que realizan actos de maldad y crueldad física o emocional. La noción de que "hombres o mujeres comunes" cometen atrocidades es real, tanto como para recordar que la maldad surge comúnmente del pensamiento corriente, cometida por gente común, ordinaria, y esta tristemente suele ser la norma en las instituciones y no la excepción.

En cuanto a la banalidad del heroísmo, Zimbardo menciona que, tanto la banalidad del mal como la del heroísmo, ninguna de las dos es consecuencia directa de tendencias o disposiciones especiales. Argumenta que ni en la psique, ni en el genoma del ser humano hay atributos especiales para la patología o la bondad. Las dos condiciones surgen en unas situaciones y en momentos determinados, cuando las fuerzas situacionales impulsan a ciertas personas a pasar de la pasividad a la acción.

El autor afirma que hay un momento decisivo en el que la persona se ve atrapada por las fuerzas que emanan de un contexto conductual. Estas fuerzas se combinan para aumentar la probabilidad de que la persona actúe para dañar a otras personas o para ayudarlas. Lo esencial, dice, es descubrir cómo limitar o evitar las fuerzas situacionales y sistémicas que impulsan a algunos de nosotros hacía la patología social. Lo importante de todo esto, es reconocer que cualquiera de nosotros puede también convertirse fácilmente en un héroe y que todos somos héroes en potencia. Con esto se abre una gran posibilidad de aprender, primero a conocerse a sí mismo $y$ a tener conciencia de los factores que pueden influir en nuestros pensamientos, sentimientos y acciones. Además, en esa atenta escucha de nosotros mismos y del contexto, nos podemos permitir desarrollar conductas pro-sociales $e$ ir desaprendiendo patrones de comportamiento guiados por el "piloto automático" que nos rige, y con el que con demasiada frecuencia actuamos siguiendo guiones trillados. En ese "reaprendizaje", es necesario tomar conciencia de las veces que en el pasado nos ha ido bien o mal y detenernos a considerar si esas respuestas son adecuadas para el aquí y el ahora. Debemos entonces, aprender y hallar un momento para pensar antes de actuar, para aprender a reflexionar en la acción y poner acción sobre lo reflexionado.

El autor nos invita a aprender a resistir influencias no deseadas, y nos dice que aceptar pasivamente un sistema injusto es cooperar con ese sistema y, de ese modo, tener parte en su maldad.

En general, el libro nos ofrece alternativas bien fundadas sobre la manera de resistirnos a las influencias sociales y sistémicas que no queremos y que no necesitamos, pero que nos bombardean día a día. Zimbardo reconoce el poder de las fuerzas situacionales para influir en la mayoría de nosotros hasta el punto de hacer que actuemos mal en muchos contextos, pero también nos deja claro, que no somos esclavos de su poder. Si entendemos cómo actúan estas fuerzas podremos oponerles resistencia e impedir que nos hagan caer en 
situaciones no deseadas. Este conocimiento nos puede liberar del influjo poderoso de la conformidad, la sumisión, la persuasión y otras formas de influencia y coacción social.

Con su texto, el autor nos invita a identificar nuestros errores de juicio en el pasado, a reconocer nuestras decisiones erróneas. $Y$ por supuesto, a aprender y practicar frases mágicas, como son: lo siento, perdón, ¡me he equivocado!, jsoy responsable! Hacerlo con franqueza, reduce la necesidad de justificar nuestras acciones y de racionalizarlas.

Philipp Zimbardo nos dice: "...dejemos que entre el sol para que ilumine estos obscuros rincones de nuestra psique humana". El libro es fascinante, porque explora las debilidades y flaquezas del carácter humano, la gran facilidad con la que se puede transformar y, cómo la gente buena puede llegar a ser cruel con los demás; nos lleva a reflexionar que el mal puede existir en cualquier lugar y que el caldo de cultivo está en situaciones 0 sistemas que suelen combinar autoridad, poder $y$ dominación, cubiertas con un manto de secretismo, el cual puede suspender nuestra humanidad y despojarnos de las cualidades que más apreciamos, como: la generosidad, la bondad, la cooperación y el amor.

En suma, en el libro se nos invita a seguir un programa de diez pasos para resistir influencias no deseadas.

Para invitar a su lectura, en este espacio sólo citaremos algunos: 1. Estar atentos, es decir, hallar un "momento zen" para pensar antes de actuar, para reflexionar sobre el significado de la situación en la que nos hallamos, y en la que para garantizar la mejor resistencia, añadamos el "pensamiento crítico" y pidamos que las afirmaciones se justifiquen con pruebas. 2. Afirmar nuestra identidad personal, no permitamos que nadie nos des-individualice, ni nos coloque en una categoría o nos encasille, convirtiéndonos en un objeto. 3. Reafirmemos nuestra individualidad, expongamos con educación y con toda claridad nuestro nombre y nuestras credenciales, recordemos que el anonimato y el secretismo encubren la maldad y debilitan los lazos humanos. 4. Respetar la autoridad justa, pero rebelarse contra la injusta, en toda situación donde haya personas con autoridad.

El contenido del libro, nos invita a intentar distinguir a quienes por su sabiduría, experiencia, antigüedad o estatus especial son merecedores de respeto, de quienes ejercen autoridad injusta reclamando nuestra obediencia sin ningún fundamento, sólo porque sean "jefes". Esto nos lleva a aprender a oponerse a sistemas injustos.

Philip Zimbardo nos muestra como el ser humano puede en cualquier momento perder "el norte moral", por lo que debemos estar atentos para no perdernos; nos enseña la importancia de aprender a equilibrar nuestra perspectiva del tiempo, con la que podamos hacer entrar en juego el pasado, el presente y el futuro en función de la situación y la tarea que nos ocupe. Nos pide recordar que el poder situacional se debilita cuando el pasado y el futuro se combinan para contener los excesos del presente y dice que debemos analizar los costes y beneficios de nuestros actos en función de sus consecuencias. También invita a no sacrificar libertades personales 0 civiles por la ilusión de seguridad. Reconoce que la necesidad de seguridad es un poderoso condicionante de la conducta humana, ya que ante una supuesta amenaza a nuestra seguridad o ante la promesa de guardarnos del peligro, podemos ser manipulados hasta el punto de acabar actuando de una manera totalmente ajena a nosotros mismos.

El autor menciona que las grandes maldades siempre empiezan con pasos pequeños que parecen triviales, pero señala que la maldad es una pendiente muy resbaladiza por lo que, cuando empezamos a andar por ella es muy fácil deslizarse hasta el fondo.

De igual manera, nos recuerda la posibilidad de subir peldaños de heroísmo de poco en poco, describe con claridad, cómo el heroísmo nunca ha sido investigado sistemáticamente por las ciencias de la conducta y que comúnmente, más que en los estudios científicos, los héroes y el heroísmo han sido objeto de mayor atención en la literatura, el arte y el cine. Señala que existen innumerables fuentes que documentan los males de la existencia humana: suicidios, homicidios, índices de criminalidad en las poblaciones, etcétera, pero no es fácil hallar datos cuantitativos y cualitativos similares, sobre actividades humanas positivas; no siendo común, llevar registros de los actos de caridad, bondad o compasión que se dan en una sociedad en el transcurso de un año. Estos índices, en apariencia tan bajos, nos hacen creer que los héroes y el heroísmo son fenómenos excepcionales. No obstante, el autor menciona que el nuevo movimiento de la psicología positiva, con su rigor empírico y metodológico, ha venido a renovar el interés en lo que tiene de bueno la naturaleza humana.

Ciertamente, este nuevo paradigma, como nuevo observatorio de la conducta, posibilita conocer y acentuar lo que hay de positivo en la naturaleza humana y a minimizar los aspectos negativos que llevan tanto tiempo acaparando la atención de la ciencia psicológica. Para ello, el autor expresa, que es indispensable conocer la naturaleza del mal e identificar las debilidades $y$ flaquezas del carácter humano, y dar paso al desarrollo del autoconocimiento, el pensamiento crítico, la valentía, los cuales puedan permitir el tránsito hacía la banalidad del heroísmo y que, con sabiduría, conocimiento, coraje, humanidad, justicia, templanza y trascendencia, seamos capaces de resistirnos a la maldad en acción o maldad por inacción. Zimbardo nos invita a alejarnos de ese coro 
silencioso que mira, pero no ve, que oye, pero no escucha las injusticias comunes en el día a día.

\section{A manera de cierre}

Para concluir, queremos compartir la experiencia satisfactoria a la que nos condujo la lectura de este libro, ya que nos ha permitido aproximarnos a conocer la extrema maleabilidad de nuestra naturaleza humana y revelar e iluminar sus rincones más obscuros, para con ello entender tantas conductas deleznables; pero a la vez, nos posibilita descubrir que todos podemos ser héroes en potencia.

Las aportaciones que el autor realiza al campo de la Psicología Social son invaluables, toda vez que nos acercan al conocimiento sobre la psicología del mal y la deshumanización. Nos ayuda a distinguir, con más claridad, que en la cotidianidad suele ser muy habitual la violencia mediada y ejercida por las personas que ocupan posiciones de autoridad y en donde es común que se adopten medidas punitivas y de maltrato verbal, que reducen el amor propio y la dignidad de quien los sufre.

Zimbardo nos recuerda que somos frecuentemente proclives a la obediencia administrativa de la autoridad, en donde no basta con reconocer que nos dominan porque tienen la fuerza, pero que no nos convencen, porque no tienen la razón; y que eso no es suficiente. El autor nos invita a dar un paso más allá, con valentía y amabilidad, a expresar la defensa de nuestra integridad y porque no, también la de otros.

Finalmente, invitamos al lector de estas líneas a aproximarse a la lectura del libro: El Efecto Lucifer: El porqué de la maldad de Philip Zimbardo, ya que aporta a todos los profesionales, elementos para la reflexión, sobre todo cuando nos sugiere respetar la autoridad justa, pero rebelarnos contra la autoridad injusta; distinguir el sano deseo de ser aceptado, sin menoscabo de nuestra independencia y, sobre todo, aprender a equilibrar nuestra perspectiva del tiempo. Solo así estaremos en una posición mejor para actuar de una manera responsable y prudente.

Es desde este enfoque que podremos asumir el desarrollo de un liderazgo de servicio, una mejor gestión en las organizaciones y en nuestra propia vida. Esto a partir de nuestro propio autoconocimiento, del conocimiento de las circunstancias y de los sistemas que nos mueven.

Este libro nos recuerda y enseña que las personas somos producto de nuestros distintos entornos, pero que también podemos intervenir en ellos; reconocer nuestra vulnerabilidad humana, nuestras flaquezas comunes ante las fuerzas situacionales y sistémicas, lo cual es el primer paso para apuntalar la capacidad de resistirse a las influencias perjudiciales, las acciones malévolas y las conductas deleznables.

\section{Referencias}

Zimbardo, Philip (2011). El efecto lucifer: El porqué de la maldad. Editorial Paidós. 